\title{
The difficulties of interprofessional teamwork in diabetes care: a questionnaire survey
}

This article was published in the following Dove Press journal:

Journal of Multidisciplinary Healthcare

5 August 2014

Number of times this article has been viewed

\author{
Miyako Kishimoto ${ }^{1,2}$ \\ Mitsuhiko Noda ${ }^{2,3}$ \\ 'Department of Diabetes, \\ Endocrinology, and Metabolism, \\ Center Hospital, National Center \\ for Global Health and Medicine, \\ Tokyo, Japan; ${ }^{2}$ Diabetes and \\ Metabolism Information Center, \\ Diabetes Research Center, Research \\ Institute, National Center for Global \\ Health and Medicine, Tokyo, Japan; \\ ${ }^{3}$ Department of Diabetes Research, \\ Diabetes Research Center, Research \\ Institute, National Center for Global \\ Health and Medicine, Tokyo, Japan
}

Correspondence: Miyako Kishimoto National Center for Global Health and Medicine, I-2I-I Toyama Shinjuku-ku, Tokyo 162-8655, Japan

Tel $+8 \mid 332027181$

Fax +81332071038

Email mkishimo@hosp.ncgm.go.jp
Background: Diabetes is a multifactorial disease and its nature means that interprofessional teamwork is essential for its treatment. However, in general, interprofessional teamwork has certain problems that impede its function. To clarify these problems in relation to diabetes care, a questionnaire survey was conducted.

Methods: The participants who were involved in diabetes-related educational seminars, and medical personnel who were engaged in diabetes care from the National Center for Global Health and Medicine, were asked to complete the questionnaire about perceptions of, and satisfaction with, interprofessional teamwork across multiple health care providers, who were actually involved in diabetes care.

Results: From 456 people who were asked to take the questionnaire, 275 people answered. The percentages of the respondents according to profession who considered multidisciplinary teamwork sufficient were as follows: physicians, $20.5 \%$; nurses, $12.7 \%$; registered dietitians, $29.6 \%$; pharmacists, $21.9 \%$; physiotherapists, $18.2 \%$; and clinical laboratory technicians $15.4 \%$. Insufficient interprofessional communication and inconsistency in motivation levels among staff were frequently cited as causes of insufficient teamwork. All professions considered interprofessional meetings or conferences necessary and essential for teamwork.

Conclusion: The survey revealed that interprofessional teamwork in diabetes care is currently insufficient. Continuous efforts to change each profession's perceptions about interprofessional teamwork and efforts to improve the quality of interprofessional meetings are necessary.

Keywords: diabetes, interprofessional, questionnaire survey, communication

\section{Introduction}

The number of people worldwide with diabetes has increased enormously; 382 million people were reported to have diabetes in 2013 and this is expected to rise to 592 million in 2035, ${ }^{1}$ which will create a significant health care burden worldwide. Nutrition therapy and exercise therapy are fundamental for diabetes, while pharmacotherapy is adopted when necessary. Therefore, not only are physicians and nurses greatly involved in patient treatment for people with diabetes, but so too are registered dietitians, physiotherapists, clinical laboratory technicians, and pharmacists. Thus, the disease requires the skill and talents of multiple health care providers, and as such, interprofessional teamwork is extremely important for diabetes care., ${ }^{2,3}$ Successful interprofessional teamwork - in other words, when multiple health workers from different professional backgrounds work together and are able to provide comprehensive services effectively by working with patients, their families, caregivers, and communities - leads to better patient care and safety, and improves health outcomes 
for patients. ${ }^{4-7}$ Therefore, it is not an exaggeration to say that the level of success of interprofessional teamwork may determine diabetes care outcomes. However, levels of perceptions of, and satisfaction with, interprofessional teamwork in multiple health care providers, who are actually involved in diabetes care, are unclear and often unexpressed. To clarify these points, a survey was conducted.

\section{Methods}

The National Center for Global Health and Medicine (NCGM) in Japan has been conducting free educational seminars five to six times per year for more than 5 years for various professional groups that are involved and interested in diabetes care. ${ }^{8}$ Participants from NCGM educational seminars and other related seminars, as well as NCGM medical personnel who are engaged in diabetes care, were asked to inform us of their profession and complete a survey featuring three questions. Question 1 (Q1) was "Do you think multidisciplinary teamwork for diabetes patients in your facility works sufficiently?" which required a "yes", "no", or "not sure" response. Question 2 (Q2) was "Why do you think so? Please explain the reasons for this." Question 3 (Q3) was "Please state your ideas regarding how to resolve this problem.” Q2 and Q3 were answered by free description. The questionnaire was anonymous and its completion was voluntary. The answers for Q1 were broken down into percentages for "yes", "no", or "not sure" in each profession. Those who answered "no" and "not sure" to Q1 were further analyzed by combining the answers for Q2, and the substantially similar answers for Q2 were grouped and categorized into themes.

\section{Results}

From a total of 465 people who were asked to take the questionnaire (432 seminar participants and 33 NCGM medical staff) 275 people answered the questionnaire (243 seminar participants and 32 NCGM medical staff). The percentages of each occupation that answered "yes", "no", and "not sure" to Q1 are shown in Table 1. These figures show that less than $30 \%$ of the participants in each of the professions surveyed were satisfied regarding the current state of interprofessional teamwork. The percentages of "yes" answers in each profession were as follows: physicians, $20.5 \%$; nurses, $12.7 \%$; registered dietitians, 29.6\%; pharmacists, $21.9 \%$; physiotherapists, 18.2\%; and clinical laboratory technicians, $15.4 \%$.

Representative answers to Q2 and Q3 for each profession are shown in Table 2. The answers for Q2 were varied, and those who answered "no" and "not sure" to Q1 were
Table I Answers to Question I

\begin{tabular}{lllll}
\hline Profession & Yes & No & Not sure & Nonresponse \\
\hline Doctor & $9(20.5 \%)$ & $17(38.6 \%)$ & $15(34.1 \%)$ & $3(6.8 \%)$ \\
Nurse & $13(12.7 \%)$ & $44(43.1 \%)$ & $36(35.3 \%)$ & $9(8.8 \%)$ \\
$\begin{array}{l}\text { Registered } \\
\text { dietitian }\end{array}$ & $16(29.6 \%)$ & $22(40.7 \%)$ & $12(22.2 \%)$ & $4(7.4 \%)$ \\
$\begin{array}{llll}\text { Pharmacist } \\
\text { Physical }\end{array}$ & $7(21.9 \%)$ & $14(43.8 \%)$ & $8(25.0 \%)$ & $3(9.4 \%)$ \\
$\begin{array}{l}\text { therapist } \\
\text { Clinical }\end{array}$ & $2(15.4 \%)$ & $4(36.4 \%)$ & $4(36.4 \%)$ & $1(9.1 \%)$ \\
$\begin{array}{l}\text { laboratory } \\
\text { technician }\end{array}$ & & & & \\
Other & $3(15.8 \%)$ & $4(21.0 \%)$ & $6(31.6 \%)$ & $6(31.6 \%)$ \\
\hline
\end{tabular}

Notes: Answers within each profession to the question, "Do you think interprofessional teamwork for diabetes patients in your facility works sufficiently?" The numbers in each column indicate the number and percentages within each profession who answered "Yes", "No", or "Not sure". The number and percentages of nonresponses were also recorded.

classified into five thematic categories. The answers that considered lack of interprofessional communication as the main obstacle to interprofessional teamwork were categorized in "Insufficient communication": for example, answers such as "Because we do not have regular interprofessional meetings, we have no opportunity to communicate and exchange patients" information", or "We can communicate with physicians, but it is hard to communicate with other professions, such as physical therapists or clinical laboratory technicians." The answers that consider lack of a leader, such as a diabetologist or a certified diabetes educator, as the main problem were categorized under "Lack of leader". The answers that considered lack of labor as the fundamental problem - in other words, that lack of labor leads to busy medical staff and makes them devote so much to their own professional daily duties that they cannot participate in any additional interprofessional teamwork - were categorized under "Lack of labor". The answers that considered the conditions of medical facilities as the main problem - for example, "Because there are only one doctor and two nurses in our clinic, we cannot work together with dietitians or pharmacists" - were categorized under "Condition of facilities". Finally, the answers that considered inconsistencies of staff motivation levels among relevant staff as the main problem were categorized in "Inconsistent motivation" (eg, answers such as "There are big gaps of motivation among the professions or among the individual team members. Even if I propose something, other members do not react").

The percentages for each occupation's answers that were classified into the thematic categories of "Insufficient communication", "Lack of leader", "Lack of labor", "Condition of facilities", and "Inconsistent motivation" are shown in Table 3. 
Table 2 Representative answers to Questions 2 and 3

\begin{tabular}{ll}
\hline Profession & Explanations \\
\hline Doctor & Reasons for "Yes" \\
- Conferences are being held and staff can share patients' information. \\
Reasons for "No" \\
- Opportunities for interprofessional communication are infrequent. \\
- Role sharing among professionals is imperfect. \\
- Education for medical staff is still insufficient. \\
- Each professional is required to prioritize their own section's work and it is difficult to work as a member of an \\
- interprofessional team regardless of section and bases. \\
- Interprofessional coordination is difficult especially at a university hospital. \\
Reasons for "Not sure"
\end{tabular}

- Interprofessional communication among the staff in the ward is successful but among staff at the outpatient clinic, it is not working well. In addition, the sharing of patients' information between staff at the ward and staff at the outpatient clinic is insufficient.

- We are trying to create this, but because we are working at a small clinic, the system for interprofessional teamwork has not yet been established.

Proposal for improvement

- Try to provide more opportunities for interprofessional communication between staff in the ward and staff at the outpatient clinic.

Nurse Reasons for "Yes"

- Educational classes for patients are conducted by multidisciplinary medical personnel.

- Each professional seems to be fulfilling his or her duties.

- At small medical facilities, such as the clinic, nurses and physicians see patients together and cooperate well.

Reasons for "No"

- Doctors just give directions and are not inclined to discuss things with us.

- Thinking that physicians may be busy, we tend to hesitate asking questions or proposing an idea about patient care.

- There are gaps in the motivation levels of team members.

- Other professions, especially physicians, seem not to be willing to collaborate positively with us.

- Because I am working at a small clinic, I have no chance to talk with patients and check their medical records. I feel that physicians do not expect nurses to educate patients much.

- No interprofessional conferences exist.

- Nurses lack knowledge about diabetes care because nurses have to learn and experience a wide medical field.

- Too busy to have detailed conversations with other staff or patients.

- Rely on physicians too much. Other nonphysician staff are unmotivated.

- Some nurses are reluctant to involve other professions.

- Educational classes for diabetic patients have been conducted; however, no discussion or feedback is provided among the lecturers.

- Each professional is required to prioritize their own sectional work and it is difficult to work as a member of an interprofessional team.

Reasons for "Not sure"

- No coordination and information sharing between staff engaged in the outpatient clinic and hospital ward.

- We have a chance to discuss things with doctors and dietitians at conferences but have hardly any chance to discuss things with physiotherapists or clinical laboratory technicians.

- Physicians are too busy to attend conferences.

- At interprofessional meetings, physicians take the lead in decisions, and ideas or comments from other professions are hardly adopted.

- There are big differences in the levels of knowledge and motivation for diabetes care among interprofessional team members.

- Doctors' understanding and cooperation for medical care provided by nurses is insufficient.

- Other staff are not cooperative and are unmotivated. I am the only certified diabetes educator in my hospital and to manage interprofessional teamwork is a large burden for me.

- We are proud that we are doing well, but the person who is central to an interprofessional team will be retiring soon.

We want to recruit new staff; however, the young staff do not seem to show motivation toward diabetes care.

Proposals for improvement

- To make more time to talk with patients and to discuss with other professionals; efforts to increase the number of staff, and efforts to create a better environment for patient care, will be necessary.

- Hold interprofessional meetings or conferences regularly. 
Table 2 (Continued)

\begin{tabular}{|c|c|}
\hline Profession & Explanations \\
\hline Registered dietitian & $\begin{array}{l}\text { Reasons for "Yes" } \\
\text { - Interprofessional meetings work well and are helpful to share patients' information. } \\
\text { - Because I am working at a small clinic, I can share patients' information with other staff frequently during my } \\
\text { spare time. } \\
\text { - Interprofessional teams both at the outpatient clinic and hospital ward are working efficiently. } \\
\text { - Certified diabetes educators are contributing their professional skills and knowledge. } \\
\text { - Physicians take the lead during interprofessional teamwork. } \\
\text { Reasons for "No" } \\
\text { - There are big differences in the levels of knowledge and motivation for diabetes care among interprofessional } \\
\text { medical staff. } \\
\text { - Certified diabetes educators in my clinic work part-time and their motivation is decreasing. } \\
\text { - Interprofessional meetings are insufficient. } \\
\text { - Owing to the lack of labor, we have no time for additional interprofessional teamwork. } \\
\text { Reasons for "Not sure" } \\
\text { - Pharmacists and physiotherapists are not attending interprofessional meetings or conferences. } \\
\text { - Because of different ideologies and aims among interprofessional team members, sometimes it is difficult to gain } \\
\text { consensus for things that need to be decided. } \\
\text { - We have educational classes for patients; however, lectures are becoming monotonous. } \\
\text { Proposals for improvement } \\
\text { - Each staff member should develop knowledge and experience regarding diabetes care to contribute as a member of an } \\
\text { interprofessional team. } \\
\text { - Each staff member needs self-improvement to give full play to his or her ability. } \\
\text { - Establish an effective system to coordinate interprofessional team members. }\end{array}$ \\
\hline Pharmacist & $\begin{array}{l}\text { Reasons for "Yes" } \\
\text { - Regular interprofessional meetings are conducted regarding educational classes for diabetic patients. } \\
\text { Reasons for "No" } \\
\text { - There is no physician specializing in diabetes. We cannot perform interprofessional teamwork without a specialist. } \\
\text { - We have interprofessional meetings but we are not exchanging patients' information. } \\
\text { - There is no interprofessional communication. } \\
\text { Reasons for "Not sure" } \\
\text { - The present hospital I am working at seems to me less enthusiastic to partake in interprofessional teamwork compared } \\
\text { to my previous workplace. } \\
\text { - I am working at a small hospital. There are only two pharmacists, one dietitian, and two clinical laboratory technicians and } \\
\text { only now are we planning to work as an interprofessional team. } \\
\text { - Team members cooperate well; however, because we are not engaged in diabetes care exclusively, we cannot spare } \\
\text { enough time. } \\
\text { Proposal for improvement } \\
\text { - Increase the number of interprofessional meetings to understand more profoundly the duties of the other professions. }\end{array}$ \\
\hline Physiotherapist & $\begin{array}{l}\text { Reasons for "Yes" } \\
\text { - The staff in every occupation are involved in a patient's care. } \\
\text { Reasons for "No" } \\
\text { - Because of lack of labor and time, we cannot attend the meetings. } \\
\text { - Not all professions are attending the interprofessional meetings. } \\
\text { Reasons for "Not sure" } \\
\text { - There are big differences in the levels of knowledge and motivation for diabetes care among team members. } \\
\text { Proposal for improvement } \\
\text { - Increase the number of staff so that we can attend the meetings and have more time to talk with patients. }\end{array}$ \\
\hline $\begin{array}{l}\text { Clinical laboratory } \\
\text { technician }\end{array}$ & $\begin{array}{l}\text { Reasons for "Yes" } \\
\text { - Regular interprofessional meetings are held every week and we can share patients' information. } \\
\text { Reasons for "No" } \\
\text { - The sharing of patient information is not sufficient. } \\
\text { Reasons for "Not sure" } \\
\text { - The staff are lacking self-direction. } \\
\text { Proposal for improvement } \\
\text { - Improve the quality of interprofessional meetings. }\end{array}$ \\
\hline
\end{tabular}

Notes: The representative descriptions from each profession regarding the reasons for their answers to the question and their proposals to improve the current situation. 
Table 3 Thematic analysis

\begin{tabular}{lllllll}
\hline & Doctor & Nurse & $\begin{array}{l}\text { Registered } \\
\text { dietitian }\end{array}$ & Pharmacist & $\begin{array}{l}\text { Physical } \\
\text { therapist }\end{array}$ & $\begin{array}{l}\text { Clinical laboratory } \\
\text { technician }\end{array}$ \\
\hline Insufficient communication & $10(43.5)$ & $32(42.7)$ & $11(35.5)$ & $7(36.8)$ & $2(100.0)$ & $3(30.0)$ \\
Lack of leader & $3(13.0)$ & $2(2.7)$ & $4(12.9)$ & $5(26.3)$ & $0(0.0)$ & $0(0.0)$ \\
Lack of labor & $3(13.0)$ & $12(16.0)$ & $3(9.7)$ & $1(5.3)$ & $0(0.0)$ & $1(10.0)$ \\
Condition of facilities & $6(26.1)$ & $12(16.0)$ & $1(3.2)$ & $6(31.6)$ & $0(0.0)$ & $2(20.0)$ \\
Inconsistent motivation & $1(4.3)$ & $17(22.7)$ & $12(38.7)$ & $0(0.0)$ & $0(0.0)$ & $4(40.0)$ \\
\hline
\end{tabular}

Notes: The reasons why each profession answered "No" or "Not sure" to the question "Do you think multidisciplinary teamwork for diabetes patients in your facility works sufficiently?" were classified into five main themes. Each column shows the number and percentages within each profession in this thematic analysis.

For physicians, nurses, pharmacists, and physical therapists, "Insufficient communication" is the most concerning issue as the obstacle to interprofessional teamwork, whilst registered dietitians and clinical laboratory technicians considered "Inconsistent motivation" as the most concerning issue.

\section{Discussion}

The present questionnaire survey indicated that the current situation regarding interprofessional teamwork for diabetes care is considered problematic and insufficient among the medical personnel surveyed and that there is much room for improvement. Previous research regarding multidisciplinary teamwork has shown that successful interprofessional teamwork helped to achieve intensive glycemic control in certain patient groups. ${ }^{4}$ However, interprofessional teamwork in general, not solely within diabetes care, has certain difficulties in clinical settings. Caldwell and Atwal ${ }^{9}$ summarized the problems associated with interprofessional teamwork as involving four issues: ideological differences between health care professions, unequal power relations between the health professions, communication within and between the professional groups, and role overlap and confusion. The results of the present questionnaire survey also showed the communication difficulties within diabetes care.

The Diabetes Attitudes Wishes and Needs 2 (DAWN2) study ${ }^{10}$ aims to provide a holistic assessment of diabetes care and management among people with diabetes, family members, and health care professionals. The questionnaire results in the DAWN2 study showed that $63.0 \%$ of responders recognized the need for formal training in effective communication for all diabetes care specialists, and $56.1 \%$ of responders recognized that there should be better communication within the team. ${ }^{11}$

In the present study, physicians considered insufficient interprofessional communication, condition of medical facilities they worked at, and lack of labor as problems needing to be solved. Nurses considered insufficient communication with physicians or with other professions to be the main problems, as well as inconsistencies of staff motivation levels. Both physicians and nurses considered that insufficient interprofessional communication was the main problem; physicians were not likely to realize that relationships between physician and nonphysician staff are key, while nurses specifically consider that physicians should be more cooperative with them and should understand the need for open communication with them. In addition, physicians seem not to care so much about inconsistent motivation among the team members, while nurses are very concerned about it. Other professions also considered insufficient interprofessional communication or inconsistencies of staff motivation levels as the main problem to be solved. All professions considered that interprofessional meetings or conferences were necessary and essential; however, many people were not satisfied with the ongoing meetings and considered that the meeting content and structure, as well as the members, needed to be changed.

Frequent, high-quality communication and strong relationships among health care providers are important to maximize the quality of care, improve the efficiency of care, and improve clinical outcomes. ${ }^{5,12-14}$ However, according to the present survey results, some medical personnel have difficulty communicating with other professionals or have never experienced interprofessional meetings or conferences.

Unequal power - in other words, hierarchy - is another main issue regarding teamwork and communication difficulties. ${ }^{5,15-19}$ While better communication and the development of relationships between health care professionals can be valuable, even within a hierarchical system, ${ }^{12}$ nonphysician staff remain reluctant to complain to other professionals, particularly physicians. A previous study using a questionnaire to clarify physicians' traits that impede effective nurse-physician communication revealed that physicians' reluctance to communicate with nurses and physicians' emotional difficulties were the main reasons for the communication barrier. ${ }^{20}$ The authors suggested that educating 
future physicians or residents to have a positive attitude toward open communication with nurses might reduce the communication barrier. ${ }^{20}$ Although physicians are often the leaders of interprofessional teamwork, diabetes educators ${ }^{21-24}$ can be leaders in facilitating open communication among members and preventing the problems associated with hierarchical relationships.

Any division of health care across multiple professions can provoke conflict, particularly in areas featuring potential role overlap. ${ }^{12}$ It is desirable for professionals to support each other and assist with work that one may be unable to conduct because of a lack of labor or personal inexperience. However, when there are instances of overlapping work with two or more professions involved - for example, a nurse and a pharmacist teaching the same patient at different times how to self-inject insulin via different procedures - and each professional does not share their information with the other, the situation may become confusing, leaving the patient in a potentially dangerous situation. In order to resolve this, each profession should define its role in the team and teams should establish strategies to encourage working partnerships. ${ }^{9}$ If each profession can teach consistent content to patients, it will be beneficial for patients to obtain reinforcement from different professionals.

Previous reports suggest the effectiveness of postgraduate medical education or interprofessional training programs to educate professionals regarding the importance of interpro-

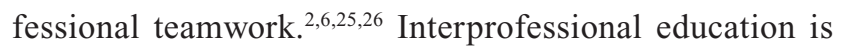
believed to enhance learners' understanding of other professions' roles and responsibilities, while fostering mutual respect and understanding between members of a health care team. ${ }^{7}$ To evaluate the kinds of education or $\operatorname{program}(\mathrm{s})$ that will be effective in improving interprofessional teamwork, further study featuring a large sample size and a well-thoughtout design will be necessary.

There are some limitations in the present survey. Firstly, because of the nature of the term "interprofessional teamwork", its meaning may vary between individuals and respondents might have difficulties in answering questions. This might be one of the reasons why many respondents answered "not sure" to Q1, instead of giving more definite answers such as "yes" or "no". Secondly, because the questionnaire was conducted for the participants of the educational diabetes seminars who might be more enthusiastic and highly motivated in diabetes care than persons who did not attend the seminars, the results might be biased and not representative in general. The lack of data regarding number of persons who refused to answer the questionnaire raises questions about the representativeness of the samples. Thirdly, the questionnaire did not ask age, sex, or type of facility at which the respondents were working. The information about these factors might give us additional insights. Actually, as shown in Tables 2 and 3, some respondents answered that interprofessional teamwork is insufficient because they are working at medical facilities that are either too small or too big - for example, a small clinic or a university hospital. Therefore, we should have asked in the questionnaire about the types of medical facilities at which respondents were working. Further study that includes this information with a larger number of medical personnel will be necessary.

\section{Conclusion}

In conclusion, the results of the questionnaire survey regarding interprofessional teamwork in diabetes care revealed some difficulties in conducting teamwork. Changing the organizational structure and team-leadership style in a short period may be difficult, but continuous efforts to change each profession's perception of multidisciplinary teamwork and efforts to improve the quality of interprofessional meetings are vital. In addition, physicians need to be better at recognizing the need for open communication and at accepting feedback or input from other professions. To promote this, certain training in effective communication at the start of their professional career, such as when they are students, may be effective.

\section{Disclosure}

The authors report no conflicts of interest in this work.

\section{References}

1. International Diabetes Federation. IDF Diabetes Atlas: 6th Edition. 2013. Available from: http://www.idf.org/diabetesatlas. Accessed July 2, 2014.

2. Dounis G, Ditmyer M, Vanbeuge S, et al. Interprofessional faculty development: integration of oral health into the geriatric diabetes curriculum, from theory to practice. J Multidiscip Healthc. 2013;7:1-9.

3. Ritholz MD, Beverly EA, Abrahamson MJ, Brooks KM, Hultgren BA, Weinger K. Physicians' perceptions of the type 2 diabetes multidisciplinary treatment team: a qualitative study. Diabetes Educ. 2011;37(6):794-800.

4. Warrington L, Ayers P, Baldwin AM, et al. Implementation of a pharmacist-led, multidisciplinary diabetes management team. Am J Health Syst Pharm. 2012;69(14):1240-1245.

5. Minamizono S, Hasegawa H, Hasunuma N, Kaneko Y, Motohashi Y, Inoue Y. Physician's perceptions of interprofessional collaboration in Clinical Training Hospitals in Northeastern Japan. J Clin Med Res. 2013;5(5):350-355.

6. Health Professions Network Nursing and Midwifery Office within the Department of Health Resources for Health. Framework for Action on Interprofessional Education and Collaborative Practice. Geneva: World Health Organization; 2010. Available from: http://www.who.int/hrh/ resources/framework_action/en/. Accessed July 2, 2014. 
7. Curran VR, Sharpe D, Forristall J. Attitudes of health sciences faculty members towards interprofessional teamwork and education. Med Educ. 2007;41(9):892-896.

8. Kishimoto M, Noda M. A report on diabetes seminars for medical staff: findings from a questionnaire survey. Diabetol Int. 2013;4(4): 261-265.

9. Caldwell K, Atwal A. The problems of interprofessional healthcare practice in hospitals. Br J Nurs. 2003;12(20):1212-1218.

10. Peyrot M, Burns KK, Davies M, et al. Diabetes Attitudes Wishes and Needs 2 (DAWN2): a multinational, multi-stakeholder study of psychosocial issues in diabetes and person-centered diabetes care. Diabetes Res Clin Pract. 2013;99(2):174-184.

11. Holt RI, Nicolucci A, Kovacs Burns K, et al. Diabetes Attitudes, Wishes and Needs second study (DAWN2 ${ }^{\mathrm{TM}}$ ): cross-national comparisons on barriers and resources for optimal care - healthcare professional perspective. Diabet Med. 2013;30(7):789-798.

12. Whitehead $\mathrm{C}$. The doctor dilemma in interprofessional education and care: how and why will physicians collaborate? Med Educ. 2007;41(10): 1010-1016.

13. Schmidt I, Claesson CB, Westerholm B, Nilsson LG, Svarstad BL. The impact of regular multidisciplinary team interventions on psychotropic prescribing in Swedish nursing homes. J Am Geriatr Soc. 1998;46(1): 77-82.

14. Wilson SF, Marks R, Collins N, Warner B, Frick L. Benefits of multidisciplinary case conferencing using audiovisual compared with telephone communication: a randomized controlled trial. J Telemed Telecare. 2004;10(6):351-354.

15. Manser T. Teamwork and patient safety in dynamic domains of healthcare: a review of the literature. Acta Anaesthesiol Scand. 2009;53(2):143-151.

16. McCulloch $\mathrm{P}$, Rathbone J, Catchpole $\mathrm{K}$. Interventions to improve teamwork and communications among healthcare staff. $\mathrm{Br} J$ Surg 2011;98(4):469-479.
17. Greenberg CC, Regenbogen SE, Studdert DM, et al. Patterns of communication breakdowns resulting in injury to surgical patients. $\mathrm{J} \mathrm{Am}$ Coll Surg. 2007;204(4):533-540.

18. Rosenstein AH, O'Daniel M. Impact and implications of disruptive behavior in the perioperative arena. J Am Coll Surg. 2006;203(1): 96-105.

19. Kennedy TJ, Regehr G, Baker GR, Lingard L. Preserving professional credibility: grounded theory study of medical trainees' requests for clinical support. BMJ. 2009;338:b128.

20. Morinaga K, Ohtsubo Y, Yamauchi K, Shimada Y. Doctors' traits perceived by Japanese nurses as communication barriers: a questionnaire survey. Int J Nurs Stud. 2008;45(5):740-749.

21. Kawaguchi T. Certified diabetes expert nurse and nurse educators in Japan. Diabetes Res Clin Pract. 2007;77(Supp1 1):S205-S207.

22. Kahn LS, Tumiel-Berhalter L, D'Aniello R, et al. The impact of "growing our own": a pilot project to address health disparities by training health professionals to become certified diabetes educators in safety net practices. Diabetes Educ. 2012;38(1):86-93

23. Moran K, Burson R, Critchett J, Olla P. Exploring the cost and clinical outcomes of integrating the registered nurse-certified diabetes educator into the patient-centered medical home. Diabetes Educ. 2011;37(6): 780-793.

24. Burke SD, Sherr D, Lipman RD. Partnering with diabetes educators to improve patient outcomes. Diabetes Metab Syndr Obes. 2014;7: 45-53.

25. Hojat M, Nasca TJ, Cohen MJ, et al. Attitudes toward physician-nurse collaboration: a cross-cultural study of male and female physicians and nurses in the United States and Mexico. Nurs Res. 2001;50(2): $123-128$.

26. Vanderwielen LM, Vanderbilt AA, Dumke EK, et al. Improving public health through student-led interprofessional extracurricular education and collaboration: a conceptual framework. $J$ Multidiscip Healthc. 2014; 7:105-110.
Journal of Multidisciplinary Healthcare

\section{Publish your work in this journal}

The Journal of Multidisciplinary Healthcare is an international, peerreviewed open-access journal that aims to represent and publish research in healthcare areas delivered by practitioners of different disciplines. This includes studies and reviews conducted by multidisciplinary teams as wel as research which evaluates the results or conduct of such teams or health-

\section{Dovepress}

care processes in general. The journal covers a wide range of areas and welcomes submission from practitioners at all levels, from all over the world The manuscript management system is completely online and includes a very quick and fair peer-review system. Visit http://www.dovepress.com/ testimonials.php to read real quotes from published authors. 